\title{
PrÁxis E JOGO: COMENTÁRIOS ACERCA DA DIALÉTICA DE UM TEATRO PÓS-VANGUARDA ${ }^{1}$
}

\author{
Christoph Menke
}

\section{Resumo}

Este ensaio discute a posição de práticas teatrais pós-dramáticas em relação aos movimentos da vanguarda teatral no início do século XX, abordando a reivindicação do teatro pós-dramático de ser também um teatro pós-vanguardista. $\mathrm{O}$ autor tece reflexões sobre a peça didática de Brecht a partir das considerações de Benjamin, principalmente sobre o texto "A decisão", para elaborar uma análise como o fracasso do jogo teatral perante a práxis inscrita nas experiências das vanguardas se torna o objeto e o conteúdo do jogo teatral no teatro pós-dramático. Nessa perspectiva, o teatro pós-dramático revela uma prática "metadramática” ao invés de "não-dramático”.

Palavras-chave: teatro pós-dramático, vanguardas teatrais, Bertolt Brecht, Walter Benjamin.

A expressão "pós-dramática”, que Hans-Thies Lehmann propõe como conceito descritivo de um campo inteiro de formas teatrais contemporâneas, situa seu objeto de estudo dentro de uma perspectiva histórica: “após” o teatro dramático. Mas "após" aqui significa ao mesmo tempo "não”, ou mais precisamente "não mais”. Esse aspecto não mais dramático dentro do pós-dramático - esta dialética ainda faz parte da superação da dialética "dramática”, da dialética em forma de e

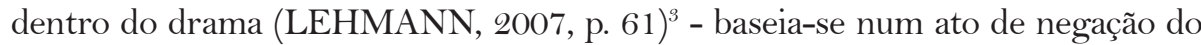
dramático que, no entanto, acha seu fundamento no próprio dramático; trata-se de uma negação "determinada”, não de uma negação "abstrata”. Por isso, Lehmann também pode dizer que o pós - ou não mais dramático surge do próprio dramático

This essay discusses the position of postdramatic theatre practices in relation to the avant-garde theatre at the beginning of the 20th century, inquiring the qualification of postdramatic theatre as postavant-garde theatre. The author reflects on Benjamin's considerations as regards Brecht's learning play "Measure Taken", in order to elaborate a discussion on the possibilities of how to incorporate into the theatrical play of postdramatic theatre the experience of avant-garde theatre's failure to make its theatrical play efficient in practical terms. From this point of view, postdramatic theatre reveals its metadramatic, rather than non-dramatic character.

Keywords: postdramatic theatre, avant-garde theatre, Bertolt Brecht, Walter Benjamin.

Junho 2010 - № 14
${ }^{1}$ Texto originalmente publicado sob 0 título "Praxis und Spiel. Bemerkungen zur Dialektik eines postavantgardistischen Theaters In: PRIMAVESI, Patrick; SCHMITT, Olaf A. (orgs.) AufBrüche. Theaterarbeit zwischen Text und Situation. (Recherchen 20). Theater der

Zeit: Berlin, 2004.

Tradução de Stephan Baumgärtel, professor do Departamento de Artes Cênicas da UDESC.

${ }^{2}$ Christoph Menke é professor da Universidade Potsdam e membro do grupo de pesquisa da Deutsche Forschungsgemeinschaft "Ästhetische Erfahrung im Zeichen der Entgrenzung der Künste/Experiência estética sob a marca da dissolução de fronteiras nas artes". Publicações, entre outras: Die Sou 


\section{Urdimento}

veränität der Kunst (Frankfurt/M., 1991), Politische Philosophie nach Adorno und Derrida (Frankfurt/M., 2004), Die Gegenwart der Tragödie. Versuch über Urteil und Spiel (Frankfurt/M., 2005), junto com Bettine Menke editou Tragödie-TrauerspielSpektakel (Berlin, 2007).

${ }^{3} \mathrm{As}$ páginas referemse à edição brasileira do livro LEHMANN, Hans-Thies. $O$ teatro pós-dramático de trad. Pedro Süssekind. São Paulo: Cosac\&Naify, 2007.

4"0 desejo das vanguardas de superar as fronteiras entre a vida e a arte (uma tentativa cujo valor evidentemente não é aniquilado pelo seu fracasso) foi também um motivo da reteatralização" (p. 83). através da sua "autorreflexão" (idem, p.78). Pois o teatro dramático será posto em questão, para não dizer superado pelo simples fato de ser teatro: através de uma mobilização da contradictio in adiecto existente na expressão e no fenômeno "teatro pós-dramático". Pode-se chamar "dramático" um dispositivo teatral, uma teoria e prática de teatro, na qual o teatro como um todo é subordinado a um único dos seus elementos particulares - ao texto e a seus agentes e modos de realização, como o autor e o diretor, como o princípio de interpretação e a construção de um sentido. Deste modo, o teatro seria a representação de uma "ação". O teatro se torna pós-dramático quando surge na teoria e, sobretudo, na prática teatral, uma consciência do poder e da lógica independente desse elemento subordinado, mais especificamente, uma consciência "da autonomia dos elementos não literários do teatro” (idem, p.74) em relação ao texto dramático. Portanto, o impulso da "autorreflexão" do teatro dramático não significa, como em atitudes tradicionais, um impulso para a fundamentação deste, senão para a sua dissolução: dissolução da equivalência harmônica entre texto e teatro enquanto ilusão ideológica. A autorreflexão do teatro dramático leva, em primeiro lugar, a uma "decomposição" - a "decomposição do todo de um gênero em seus elementos isolados" (idem, p.83) - e, por fim, a uma inversão da hierarquia entre teatro e texto (idem, p.91), mais do que isso, a uma emancipação (idem, p.75) do teatro da dominância textual.

Lehmann caracterizou tal processo, que parte de uma autorreflexão e leva à emancipação do teatral passando por uma decomposição da relação texto-teatro, como um processo de uma crescente "radicalização". Só em relação a esta última formação é possível falar de um "teatro pós-dramático" strictu sensu. Esse é um teatro que, na sua pressuposição teatral, não mais reflete o dramático ou diferencia entre os seus componentes dramáticos e teatrais, mas um teatro em qual os significantes teatrais se tornaram "autônomos" (idem, p.104-105). Em respeito a esta formação radical, Lehmann também fala de um "teatro sem drama"; é um teatro cujos elementos são liberados da necessidade de representar dramaticamente as estruturas de uma ação. Com isso, eles podem existir segundo a sua lógica estética interna. Dentro desse processo de radicalização, Lehmann localiza as vanguardas históricas, que juntam a autorreflexão teatral com o programa de "superar as fronteiras entre arte e vida” (idem, p.83). O que me interessa. no que segue, é esta relação do teatro pósdramático com as vanguardas históricas - mais especificamente as implicações para o teatro pós-dramático que surgem do fato de este ser ao mesmo tempo um teatro pós-vanguardista. Uma resposta a essa indagação poderia ser que o teatro pós-dramático é pós-vanguardista no sentido de simplesmente radicalizar ainda mais algo que foi iniciado com as vanguardas; o teatro pósdramático seria, então, menos pós- do que radicalmente vanguardista. Uma outra resposta poderia afirmar que o fracasso das vanguardas (que Lehmann também menciona, mas do qual ele diz que não julga as vanguardas) ${ }^{4}$ é 


\section{Urdimento}

uma pressuposição que não modela somente a forma externa do teatro pósdramático, mas exerce uma função constitutiva. Neste caso, seria necessário compreender o teatro pós-dramático como um modo não derrotista de reagir a tal fracasso. No entanto, esta afirmação não pode ser reconciliada facilmente com a concepção do pós-dramático como um "teatro sem drama" - se isto significa um teatro concebido completamente sem elementos dramáticos.

A forma básica de usar a autorreflexão teatral para fins da vanguarda pode ser extraída da interpretação que Walter Benjamin dá à peça didática de Brecht. ${ }^{5}$ Pois "a consciência de ser teatro" é também constitutiva para a peça didática. Isso se expressa, por exemplo, no fato de que "aquele que mostra isto é o ator enquanto tal - "é mostrado”" (BENJAMIN, 1985, p.210), ${ }^{6}$ como diz Brecht citado por Benjamin. "Em outras palavras: $\mathrm{O}$ ator deve se reservar a possibilidade de sair artisticamente do seu personagem. Não deve abrir mão da possibilidade de, num momento oportuno, apresentar aquele que reflete (sobre o seu papel)" (idem, p.217). Isto, acrescenta Benjamin, lembra a "antiga dramaturgia tieckiana da reflexão” (idem, p.210). Mas a diferença decisiva entre a comédia romântica e a peça didática de Brecht consiste para Benjamin no fato de que "apesar de todas as suas artes em recíproca iluminação, o palco do romantismo nunca esteve em condições de fazer justiça à relação dialética basilar, a relação entre teoria e prática, pela qual ele, à sua maneira, tanto se esforçou e tão em vão quanto o faz hoje o 'teatro da atualidade”' (p.210). Eis é o cerne de uma interpretação vanguardista da autorreflexão teatral: ela afirma que a autorreflexão teatral, compreendida e usada corretamente, é um modo de uma reflexão prática. Portanto, a autorreflexão que realça a autonomia do teatro contra a representação dramática da ação, deve se manifestar, por sua vez, no interior da representação dramática da ação de tal forma que produza o efeito de uma liberdade prática. A autorreflexão teatral e pragmática, a autonomia estética dos significantes teatrais e a liberdade prática dos agentes são relacionadas "dialeticamente”.

O próprio Brecht formulou essa oposição entre o teatro dramático e a sua autorreflexão teatral numa concepção pragmática: "O teatro, tal como nos é dado ver atualmente, apresenta a estrutura da sociedade (reproduzida no palco) como algo que não pode ser modificado pela sociedade (na sala). Édipo, que pecou contra alguns dos princípios que sustêm a sociedade de sua época, é executado, os deuses tomam a si esta tarefa, e eles não são criticáveis"? Em comparação com isso, expor a liberdade da apresentação, espelhar esta liberdade no interior do apresentado, tem como consequência a criação de "condições de experiência, isto é, que haja possibilidades de conceder uma experiência contrária para cada caso, respectivamente." ${ }^{8}$ Desta forma, Édipo poderia ter escapado do seu destino através de sua autorreflexão teatral: Se ele
${ }^{5} 0$ que me interessa neste ensaio é somente o programa de Benjamin. Em respeito aos elementos da peça didática desenvolvidos pelo próprio Benjamin que podem ser usado para argumentar contra este programa, ver MÜLLER-SCHÖLL, Nikolaus. Das Theater des 'konstruktiven Defaitismus'. Frankfurt: Stroemfeld, 2000. p. $19-44$.

${ }^{6}$ As citações seguem a tradução brasileira de BENJAMIN, Walter. 0 quê é 0 teatro épico? In: BENJAMIN, Walter. Sociologia. Org. Flávio R. Kothe. São Paulo: Ática, 1985.

${ }^{7}$ BRECHT, Bertolt. Pequeno órganon para o teatro. $\S 33$. BRECHT, Bertolt. Estudos sobre o teatro. org. Aderbal Freire Filho. Rio de Janeiro: Nova Fronteira, 2005. p.141.

${ }^{8}$ Idem, §52. (tradução mais literal: "algo como condições de um experimento de modo que cada caso permitia um experimento contrário", sendo o experimento o trabalho teatral dos atores). 


\section{Urdimento}

${ }^{9}$ Idem, §52. (literalmente, em alemão "como se esta fizesse o que faz em forma de experimento").

${ }^{10}$ Idem, $§ 77$. tivesse encarado a própria sociedade contra cujos princípios ele "pecou” para ser morto em seguida - assim a lembrança de Brecht - de uma forma "como se o que faz, fosse feito por ela a título de experiência”. ${ }^{9}$ Pois onde se experimenta não reina a necessidade, mas cria-se oportunidades para comportar-se diferentemente. A aprendizagem que a peça didática promete não consiste na transmissão de diversos conteúdos, mas de uma atitude; a atitude experimental de fazer e interpretar por si mesmo; uma atitude que consegue adotar quem se torna ator de si mesmo. Os personagens no palco mostram tal atitude, e os espectadores podem imitá-la nas suas próprias vidas, "pois a forma mais leve da existência é a arte”. ${ }^{10}$ Através dessa elevação ou simplificação da existência, a arte teatral consciente de si mesma pode contribuir "para a arte maior de todas, a arte de viver" (Brecht).

Mas a crítica que Benjamin levantou contra o drama romântico vale também para esta promessa da peça didática de contribuir, através de uma autorreflexão teatral, à arte de viver na forma de uma relação experimental consigo mesma: tal promessa fracassa precisamente perante a "relação basilar" dialética entre teoria e prática. Pois, da mesma forma que as artes reflexivas do romantismo não podem transformar a prática, mas somente sustá-la, a "forma mais leve da existência na arte" mostra-se leve demais para levantar suficientemente os pesos da prática para que se abram espaços de um jogo que permitiria romper com os seus limites. O que é possível para os atores no palco, não se pode praticar fora dele. E o que fazemos na prática não pode sempre ser feito de outra forma. Para os outros, os atores e seus espectadores, pode até ser assim - mas não para aquela pessoa que age. Pois como agente, ela julga que algo é assim, e ela deve fazer por tanto isto e somente isto; como agente, ela é submetida à decisão, e portanto, a uma necessidade que nenhum jogo pode dissolver.

Na peça $A$ decisão, Brecht criou o experimento de como o caráter da ação se transforma, se os agentes se relacionam com ela que nem atores que a apresentam perante outras pessoas. A decisão consiste em uma peça dentro da peça: durante a luta revolucionária foi tomada "a decisão" de fuzilar um "jovem camarada”. Os quatro agitadores (sobreviventes) apresentam esse fato, e como se chegou a ele, para o "coro de controle" do partido através de meios teatrais. Tal apresentação tem a função de um experimento: quer-se testar se a decisão tomada na situação continua sendo válida vista à distância. Desta forma, a apresentação teatral permitiria tirar do passado um aprendizado para futuras ações. $\mathrm{O}$ trecho decisivo é aquele em que Brecht faz a vítima da decisão declarar o seu acordo: "O PRIMEIRO AGITADOR para o jovem camarada - Se for capturado eles atirarão em você, e, como vão reconhecê-lo, nosso trabalho será descoberto. Portanto temos que atirar em você e jogá-lo na mina de cal para que a cal o queime. Mas perguntamos: você vê uma saída? O Jovem CAMARADA 


\section{Urdimento}

- Não. Os três AgITAdoRes - Então perguntamos: você está de acordo? Pausa O Jovem CAMARADA - Sim”. ${ }^{11}$ O sim é necessário, pois, preparado pela pausa da reflexão, deve segurar a conexão entre ficção e ação: o reconhecimento que se obteve na ficção teatral - é correto matar o jovem camarada - pode ser realizado na ação pragmática. Mais do que isso, já foi avaliado, dentro da situação pragmática, como correto pela vítima desta ação (pois nessa situação, ela já se comportou simultaneamente como ator e espectador da ação). O sim do jovem camarada deve garantir que se possa transferir o que foi aprendizado no campo da ficção para a perspectiva da ação pragmática, sem que se abra uma lacuna ou que sobre algum resto.

No entanto, esta transferência só diz respeito ao conteúdo do julgamento e não ao elemento fundamental, sobre qual a concepção da peça didática baseia a sua pretensão de ter resolvido o problema da relação entre reflexão teatral e vida prática, como foi formulado pelo romantismo alemão: a transferência não diz respeito às atitudes que o ator assume na sua apresentação e que o agente assume na sua prática. Pois o "sim" do jovem camarada não é uma escolha tomada de forma experimental e com diversas outras opções, mas uma decisão que expressa uma necessidade: para o jovem camarada, é evidente naquela situação que ele só pode ficar fiel às suas convicções, se ele age assim. No "sim" do jovem camarada não se expressa uma consciência teatral de si mesmo: o jovem camarada não diz sim para a sua liquidação, porque ele teria logrado dominar, no teatro e através do teatro, a "arte de viver": uma relação experimental consigo mesmo e com a situação pragmática. Ao contrário, o diz porque visualiza com toda a evidência o que ele deve fazer. É prescrito a ele invariavelmente por aquilo que ele é, e em que ele crê. ${ }^{12}$

É possível alegar contra esta concepção da peça didática que a sua integração de teatro e prática está fundamentada numa compreensão errada do fazer teatral, pois reduzida. A minha objeção afirma que ela está fundamentada também numa compreensão errada do que é a prática: a peça didática não compreende o aspecto da evidência determinante, existente em todos os atos de decidir e agir; um aspecto que não pode ser resolvido em experimentos. Como uma ação é orientada por uma finalidade, determinação e até necessidade são partes integrais desta. Na sua orientação por um objetivo consiste a seriedade do ato de agir: algo está em jogo na ação, e por isso ela pode fracassar. Além disso, em toda a afirmação de objetivos realiza-se um julgamento sobre o bem e o mal. Ora, um julgamento não é um posicionamento subjetivo feito de modo experimental (que poderia ser assim ou assado), mas uma afirmação objetiva expressão de uma evidência determinante cujo poder me posiciona. No ato de julgar, eu simplesmente expresso que é assim. O fazer teatral e a apresentação teatral de uma ação estão livres dessa evidência determinante. No fazer teatral não se pronuncia julgamentos para transformá-los em ações. Exatamente por

Práxis e Jogo. Christoph Menke

${ }^{11}$ BRECHT, Bertolt. A decisão. Trad. Ingrid Dormien Kordela. In: Bertolt Brecht. Teatro Completo em 12 Volumes. Vol. 3. Rio: Paz e Terra, 1988, p.264-265.

${ }^{12} V e j a$ Brecht (1988, p.265): "O JOVEM CAMARADA invisível Ele ainda disse: No interesse do comunismo/ De acordo com o avanço das massas proletárias/ De todos os países,/ Afirmando a revolução mundial". 
isso não se pode imitar o fazer teatral na forma de uma ação pragmática. A apresentação teatral pode chamar atenção a sua própria forma (então seria uma forma de mostrar); pode desvincular a forma da finalidade e os elementos da forma dos seus respectivos contextos (nisso seria piada ou paródia); pode ensaiar outras definições do bem e outras possibilidades da sua realização (nisso seria experimento). Tudo isso são resultados da apresentação teatral de uma ação, através do qual a apresentação pode transformar tal ação. Mas a apresentação de uma ação não pode nos ensinar a agir diferentemente de modo que a sua orientação pelo Bem e a evidência do Bem se dissolvessem isto quer dizer que a ação se separasse do julgamento. Neste caso, a pessoa não iria agir de forma diferente, mas simplesmente não agiria mais. A liberdade do fazer teatral consiste no fato de que escapa do poder do julgamento. Mas essa liberdade não é, como o sim do jovem camarada, um sim que afirma uma forma de agir diferente e melhor, mas um não à ação propriamente dita.

Lehmann descreveu a (pré-)história do teatro pós-dramático como “uma espécie de hierarquia da radicalidade", que leva "de uma teatro "virtualmente ainda dramático’ até um teatro que já não há sequer rudimentos de processos fictícios" (LEHMANN, 2007, p.114). A força propulsora nesse processo de radicalização é a autorreflexão na qual se revelam, já desde o romantismo, as pressuposições teatrais da representação dramática. Além disso, contra a imagem popular de uma modernidade estética que produz inovações e experimentos como um fim em si mesmo, Lehmann apontou que só se pode compreender corretamente este processo de radicalização estética, se ele é visto como uma sequência de negações "determinadas", quer dizer, de passos fundamentados na realidade do processo: cada passo adiante no processo da radicalização estética baseia-se na experiência de uma deficiência dos passos anteriores. Este modelo geral da história do teatro pós-dramático vale também em relação ao teatro das vanguardas históricas: o teatro pós-dramático radicaliza a autorreflexão teatral até um ponto em que nenhuma liberdade prática de ação pode mais corresponder com a "autonomia dos significantes" produzida esteticamente. Com isso, a radicalização pós-dramática destrói o contexto dialético que é destinado, no teatro das vanguardas, a manter a autorreflexão teatral ligada a uma prática já dissolvida experimentalmente. No entanto, o teatro pós-dramático faz isso, porque percebe tal contexto não só como limitado, mas até frágil e obsoleto. Tal experiência é uma das pressuposições para o teatro pós-dramático. $\mathrm{Na}$ base ou no princípio do teatro pós-dramático encontra-se a experiência do fracasso das vanguardas históricas.

Analisando os problemas nos quais caem as tentativas de realizar a concepção da peça didática, a experiência do fracasso das vanguardas históricas consiste essencialmente no reconhecimento da diferença estrutural 


\section{Urdimento}

que separa o jogo da ação, o teatro da práxis. ${ }^{13}$ Só a experiência desta diferença faz o teatro pós-dramático obter a sua "consciência mais precisa da autonomia dos elementos não literários do teatro" (Lehmann, 2007, p. 76) perante a representação dramática da ação. Mas então surge a questão, onde e como o teatro pós-dramático experimenta tal diferença; como e de onde o teatro pósdramático sabe dessa diferença e, com ela, do fracasso das vanguardas em tentar a integração dialética de teoria e práxis. Uma resposta poderia ser que se trata de um conhecimento que serve como pressuposto do teatro pós-dramático. Seria, então, um conhecimento sobre o teatro - um conhecimento, portanto, da teoria (ou da crítica ou da filosofia), que não se manifesta ou expressa no palco. Contudo, a experiência da diferença entre práxis e jogo pode ser feita no próprio teatro. $\mathrm{O}$ reconhecimento que a promessa vanguardista acerca do jogo teatral - de criar uma prática livre da seriedade e da determinação - tem que ficar em aberto, não é um reconhecimento que se pode ganhar somente depois do fim da peça e quando se quiser agir. Pode ser feito antes, para não dizer de forma melhor, no próprio teatro e durante a peça: por exemplo, ao experimentar que o teatro não consegue mostrar (como o nosso breve olhar para a peça $A$ decisão tem evidenciado) uma forma de agir que seja igual ao jogo teatral, e com isso livre da seriedade e da evidência. E ao mesmo tempo, vivenciamos nessa experiência que o agir é marcado por uma diferença irrecuperável em relação ao jogo.

No teatro desta vanguarda expressa-se involuntariamente a experiência do fracasso do jogo perante a práxis; por exemplo, ao perceber que a peça didática subverte a própria programática de transformar, através do jogo teatral, a prática em jogo. O que se mostra involuntariamente no teatro também pode ser intencional: o fracasso do jogo teatral perante a práxis pode se tornar o objeto e o conteúdo do jogo teatral. Acontece, por exemplo, quando Samuel Beckett, em Fim de Partida, faz ensaiar o Clov as estratégias vanguardistas da subversão até chegar num auto-bloqueio, e quando Heiner Muller desmonta a concepção da peça didática em seus componentes. Tais formas teatrais de uma "pós-vanguarda" não pressupõem o fracasso das vanguardas históricas na tentativa de mediar (de uma forma mais ou menos 'dialética') a relação entre jogo e práxis, mas mostram e ensaiam tal fracasso na própria prática teatral. Aqui se ganha uma consciência da diferença insuperável entre práxis e teatro através do próprio fazer teatral.

A questão, onde e em que forma acontece a experiência do fracasso das vanguardas - se como pressuposto ou através do fazer teatral - leva a concepções bem distintas da forma de um teatro pós-vanguardista. Se tal experiência está pressuposta como um conhecimento crítico ou teórico, então o teatro pós-vanguardista se limita a uma liberação meramente estética do jogo teatral. Semelhante à figura Hegeliana de uma arte pós-romântica, tal
${ }^{13}$ Uso a palavra práxis, e não 'prática', pois se trata aqui do fazer teatral enquanto teoria e prática social. Práxis, diferente de prática, evoca os significados de uma prática humana voltada para o campo político e social. 


\section{Urdimento}

14"Não é possível conceber um teatro dramático em que não seja representada uma ação de uma maneira ou de outra" (LEHMANN, 2007, p. 114). teatro responde à experiência do seu potencial limitado em relação à práxis com uma auto-limitação ao que o teatro realmente consegue; os "meios da apresentação" se tornam "um fim para si mesmo", segundo a determinação de Hegel. Este teatro é radicalmente estético, ou seja: livre de finalidades externas de representação e práxis, ele pode desdobrar completamente a autonomia do jogo estético. O preço a pagar consiste no fato de que é um teatro que não pode compreender a si mesmo, pois não pode conter e expressar a própria precondição: a sua relação com a práxis. O preço por um ganho de autonomia estética no teatro é esta perda da compreensão: tanto de si mesmo como da prática da qual ele se diferencia.

Será que é necessário compreender o conceito do teatro pós-dramático seguindo esse modelo de um jogo radicalmente autônomo, mas por isso incapaz de entender a própria forma bem como o próprio pressuposto? A resposta depende como se configura a relação, em forma de negação, do pós-dramático com o dramático. Pois, se "pós-dramático" significaria não dramático e "não dramático” significaria sem drama, sem momento dramático, então o teatro pós-dramático não pode expressar a sua forma e seu pressuposto por si mesmo no próprio fazer teatral. Um teatro puramente pós-teatral seria um teatro que teria se emancipado radicalmente do dramático, mas, em contrapartida, seria incapaz de compreender a si mesmo. Pois se é correto dizer que para determinar atualmente o jogo teatral na sua relação com a práxis, a experiência da tentativa e do fracasso das vanguardas ainda é de suma importância, então um teatro que quer compreender a si mesmo tem que dispor de meios para, entre outros, levar esta experiência ao palco e representá-la. Mas a experiência e a configuração estética da investida e do fracasso das vanguardas históricas também se apresenta como a experiência e configuração de uma ação - mesma que seja um tipo de ação particular: uma ação que não é uma mera realização prática, mas que consiste na tentativa e no fracasso de transformar a lógica de manifestações práticas através do jogo teatral. Toda apresentação teatral de uma ação, no entanto, é algo dramático. ${ }^{14}$ Para que o teatro pós-dramático seja capaz de representar a própria forma em relação com o próprio pressuposto (isto é com a tentativa e o fracasso das vanguardas históricas), então o teatro pós-dramático não pode ser puramente pós-dramático, um teatro totalmente sem drama; necessita de um momento dramático, ou talvez seja melhor dizer: de uma camada dramática.

O teatro dramático subordinou o jogo teatral à representação de manifestações práticas. Ao contrário disso, o teatro das vanguardas desenvolve o jogo teatral na sua diferença com a forma dominante das manifestações práticas, mas faz isso somente para integrá-lo "dialeticamente" com uma nova forma de manifestações práticas. Pós-vanguardista é um teatro para qual esta dialética entre jogo teatral e práxis é desgastada. Um modo como o teatro 
pode reagir a esta situação após as vanguardas consiste na opção de limitarse a si mesmo, de desdobrar radicalmente o seu momento estético. Um modo diferente de reagir é o projeto de tematizar no próprio fazer teatral a relação entre teatro e práxis. Mas isso significa ao mesmo tempo compreender o termo “pós-dramático" não como "não dramático", mas simultaneamente como antie meta-dramático: um teatro pós-dramático que queira compreender a si mesmo e, com isso, na sua relação com a práxis é um teatro que levanta na própria forma a disputa entre ação e jogo, entre o dramático e o teatral.

\section{Referências bibliográficas}

BENJAMIN, Walter. O quê é o teatro épico? In: KOTHE, Flávio R. (Org.) Sociologia. São Paulo: Ática, 1985.

BRECHT, Bertolt. Estudos sobre o teatro. In: FILHO, Aderbal Freire (Org.). Rio de Janeiro: Nova Fronteira, 2005.

BRECHT, Bertolt. A decisão. Trad. Ingrid Dormien Kordela. In: Bertolt Brecht. Teatro Completo em 12 Volumes. Vol. 3. Rio de Janeiro: Paz e Terra, 1988,

LEHMANN, Hans-Thies. Oteatro pós-dramático. Tradução de Pedro Süssekind. São Paulo: Cosac\&Naify, 2007. 